\title{
UNILATERAL CONTACT AND DAMAGE ANALYSIS IN MASONRY ARCHES
}

\author{
M. Campo ${ }^{1}$, G.A. Drosopoulos ${ }^{2}$ and G.E. Stavroulakis ${ }^{2}$ \\ ${ }^{1}$ Departamento de Matemática Aplicada, \\ Facultade de Matemáticas, \\ Universidade de Santiago de Compostela, \\ ES-15782 Santiago de Compostela, Spain \\ ${ }^{2}$ Instiute of Computational Mechanics and Optimization, \\ Department of Production Engineering and Management, \\ Technical University of Crete, \\ GR-73132, Chania, Greece
}

\begin{abstract}
In the present work the ultimate failure load and the collapse mechanism of a stone arch bridge are estimated by the usage of (a) a multi - part elastic model with unilateral contact frictional interfaces and (b) a continuous damage model. According to the contact model, contact interfaces simulating potential cracks are considered and their opening or sliding indicates crack initiation. The second model deals with the material damage consisting in the development of internal microcracks that affect the load bearing capacity of the material. Satisfactory comparison of the results is reported here.

Keywords: masonry arch, limit analysis, unilateral contact, continuum damage models
\end{abstract}

\section{DESCRIPTION OF THE UNILATERAL CONTACT AND THE DAMAGE MODEL}

In this paper is presented a first step in the cooperation between a discrete and a continuum model. Objective goal of this cooperation is to study as accurately as possible structures with non linear behavior, like masonry arches.

A stone bridge consists of stone blocks and the mortar joints. Low tensile strength of the arch, which is found in the joints, contrary to the high compressive strength of the blocks, make the whole structure highly non linear.

In the present study two models are used for the calculation of the failure load and the collapse mechanism of the arch bridge. The first model [1] uses unilateral contact friction interfaces in order to describe the mechanical behavior of the arch. The model has been successfully applied to a real structure which was experimentally tested in the past [1]. The second model is a damage model [2], which was initially developed for a general use. In this study, the model is initially used for the calculation of the limit load and the collapse mechanism of a real structure. Thus, parameters of this model need to be appropriately adjusted. 
The two models are presented in the following paragraphs. Their predictions on a bridge with a concentrated force applied at the quarter span of the arch, which is probably the worst position of the live load [3], are compared.

\subsection{The unilateral contact - friction model}

The elastic model of the bridge is divided by a number of interfaces perpendicular to the center line of the arch. Unilateral contact law governs the behavior in the normal direction of an interface, indicating that no tension forces can be transmitted in this direction. The behavior in the tangential direction takes into account that sliding may or may not occur.

The unilateral contact - friction problem is a nonlinear problem in which the nonlinearity is restricted to certain interfaces or the boundary. Consequently, the equations of equilibrium are nonlinear even if the material obeys a linear elastic law or a small displacement assumption is considered. For the frictional contact problem the Virtual Work equation is written in a general form as

$$
\int_{V} \boldsymbol{\tau}: \delta \boldsymbol{\epsilon} d V=\int_{S} \delta \mathbf{u} \cdot \mathbf{t} d S+\int_{V} \delta \mathbf{u} \cdot \mathbf{f} d V+\int_{S^{\prime}} \delta \mathbf{u} \cdot \mathbf{t}^{\mathbf{n}} d S^{\prime}+\int_{S^{\prime}} \delta \mathbf{u} \cdot \mathbf{t}^{\mathbf{t}} d S^{\prime}
$$

where $\boldsymbol{\tau}$ is the stress matrix, $\delta \boldsymbol{\epsilon}$ is the virtual strain matrix; $\delta \mathbf{u}$ is the virtual displacement matrix, $\mathbf{t}$ and $\mathbf{f}$ are surface and body force vectors respectively, and $\mathbf{t}^{n}$ and $\mathbf{t}^{t}$ are the normal and tangential traction vectors on the actual contact boundary $S^{\prime}$. The contact constraint is enforced in the Virtual Work equation, with Lagrange multipliers representing the contact pressures. Lagrange multipliers are also used to enforce sticking conditions in the tangential direction. The set of the nonlinear equations is solved by the Newton Raphson incremental iterative procedure.

In the simplest case of frictionless contact, the problem can be formulated as a parametric linear complementarity problem (LCP) [4]

$$
\begin{gathered}
\mathbf{K u}+\mathbf{N}^{T} \mathbf{r}=\mathbf{P}_{o}+\lambda \mathbf{P} \\
\mathbf{N u}-\mathbf{g} \leq 0 \\
\mathbf{r} \geq 0 \\
(\mathbf{N u}-\mathbf{g})^{T} \mathbf{r}=0 .
\end{gathered}
$$

Equation (2a) expresses equilibrium equations of the unilateral contact problem without friction, $\mathbf{K}$ is the stiffness matrix and $\mathbf{u}$ is the displacement vector. $\mathbf{P}_{o}$ denotes the self weight of the structure and $\mathbf{P}$ represents the live load multiplied by the scalar parameter $\lambda$. $\mathbf{N}$ is an appropriate geometric transformation matrix and vector $\mathbf{g}$ contains the initial gaps for the description of the unilateral contact joints. Relations $(2 \mathrm{~b}),(2 \mathrm{c}),(2 \mathrm{~d})$ represent the constraints of the unilateral contact problem for the whole discretized structure, i.e. no - penetration, no - tension and either closed or open (complementarity). The enforcement of the constraints can be achieved by using Lagrange multipliers. Thus, $\mathbf{r}$ is the vector of Lagrange multipliers corresponding to the inequality constraints and is equal to the corresponding contact pressure $\left(-\mathbf{t}^{n}\right)$.

The calculation of the ultimate load is based on the exploitation of the solvability conditions for linear complementarity problems and variational inequalities. Every part of 
the bridge between two interfaces may develop rigid body displacements, which must be compatible with the constraints of the unilateral contact problem, otherwise no solution exists. In other words an equilibrium configuration may or may not exist, depending on the geometry of the structure and the direction of the applied loading. Collapse occurs at the load step of the load incrementation where solvability is first violated.

This model is presented in more details in [1].

\subsection{The damage model}

In this case, a linear elastic model is considered where the damage of the material has been taken into account. The damage is caused by the opening of internal microcracks which lead to the decrease in the load carrying capacity of the material, and, eventually, to the possible failure of the system. The material is assumed to be elastic with constitutive law

$$
\tau=\zeta \mathbf{K}(\delta \epsilon)
$$

where $\zeta$ is the scalar damage field. Following the ideas of Frémond and Nedjar $[5,6]$, the damage field is defined as an internal variable and measures the fractional decrease in the strength of the material, taking the values as the ratio

$$
\zeta=\zeta(\mathbf{x}, t)=\frac{E_{e f f}}{E}
$$

between the effective modulus of elasticity of the material $E_{\text {ef } f}$ and that of the damage-free material $E$. Due to this definition, the variable $\zeta$ varies between 0 and 1 . When $\zeta=1$ the material is damage-free, when $\zeta=0$ the material is completely damaged and for $0<\zeta<1$ it is partially damaged. Following the derivation in Frémond and Nedjar [5, 6] the evolution of the microfractures responsible for the damage is described by the differencial inclusion

$$
\dot{\zeta}-\kappa \Delta \zeta+\partial \psi_{\left[\zeta_{*}, 1\right]}(\zeta) \ni \phi(\delta \epsilon, \zeta)
$$

where $\kappa$ is the damage diffusion constant, $\partial \psi_{\left[\zeta_{*}, 1\right]}$ is the subdifferential of the indicator function of the interval $\left[\zeta_{*}, 1\right]$ ( $\zeta_{*}$ is supposed to be a lower bound for the damage) and $\phi$ is the damage source function, which contributes to the evolution of the damage depending on the mechanical stresses, and in this case has the form

$$
\phi(\delta \epsilon, \zeta)=\lambda_{1}\left(\frac{1-\zeta}{\zeta}\right)-\frac{1}{2} \lambda_{2} \delta \boldsymbol{\epsilon}^{+} \cdot \delta \boldsymbol{\epsilon}^{+}+\lambda_{3} .
$$

Here $\delta \boldsymbol{\epsilon}^{+}$is the positive part of the strain tensor, that is, only tension is supposed to contribute to the development of damage and $\lambda_{1}, \lambda_{2}$ and $\lambda_{3}$ are process parameters. The body is supposed to initially occupy a domain $\Omega$ whose boundary $\partial \Omega=\Gamma$ is divided into two disjoint parts: $\Gamma_{D}$, where the body is supposed to be fixed (homogeneus Dirichlet condition), and $\Gamma_{N}$, where surface tractions $\left(\mathbf{f}_{N}\right)$ are considered (Neumann boundary condition). In order to analyze and solve numerically this model, a variational formulation is obtained, consisting in an evolutionary variational equation for the mechanical behaviour 
and a nonlinear variational inequality for the damage evolution:

$$
\begin{gathered}
(\zeta \mathbf{K u}(t), \delta \boldsymbol{\epsilon}(\mathbf{w}))_{L^{2}(\Omega)^{2 \times 2}}=\left(f_{B}(t), \mathbf{f} w\right)_{V}+\left(f_{N}(t), \mathbf{w}\right)_{L^{2}\left(\Gamma_{N}\right)^{2}} \quad \forall \mathbf{w} \in V, \\
(\dot{\zeta}(t), \xi-\zeta(t))_{L^{2}(\Omega)}+(\nabla \zeta(t), \nabla(\xi-\zeta(t)))_{L^{2}(\Omega)^{2}} \\
\geq(\phi(\delta \boldsymbol{\epsilon}(t), \zeta(t)), \xi-\zeta(t))_{L^{2}(\Omega)}, \forall \xi \in \mathcal{K},
\end{gathered}
$$

where

$$
\begin{gathered}
V=\left\{\mathbf{f} v \in\left[H^{1}(\Omega)\right]^{2} ; \mathbf{v}=\mathbf{0} \quad \text { on } \quad \Gamma_{D}\right\} \\
\mathcal{K}=\left\{\xi \in H^{1}(\Omega) ; \zeta_{*} \leq \xi \leq 1 \quad \text { a.e. in } \Omega\right\}
\end{gathered}
$$

are the sets of admissible displacements and damage fields, respectively. Moreover, $(., .)_{X}$ denotes the inner product on the variational space X. Details about the variational and numerical analysis of this model, as well as its numerical resolution can be found in [2]. Collapse occurs at the loading step for which the whole cross-section of the bridge reaches the lower bound for the damage $\zeta_{*}$.

\section{AN APPLICATION ON A REAL SCALE MASONRY BRIDGE}

A plane stress model of stone arch bridge without fill is considered [7], as shown in Figure 1(a). Loading includes self - weight and a concentrated load at the quarter span of the bridge. Young's modulus is 5GPa, Poisson's ratio 0.3 and density $2200 \mathrm{Kg} / \mathrm{m}^{3}$.

\subsection{General}

For the contact analysis, the finite element model consists of 3036 quadrilateral, four - node, bilinear finite elements with two translational degrees of freedom per node. A typical finite element length is $0.05 \mathrm{~m}$. A load increment equal to $0.02 \mathrm{KN}$ is considered in the iterative incremental procedure. The friction coefficient is chosen equal to 0.6. This value is high enough to prevent sliding. Therefore a direct comparison of the results with the ones provided by the damage model is possible. In addition, a relatively large number of interfaces equal to 40 has been considered for the arch as the exact number of interfaces along the bridge's geometry tends to be meaningless in case many interfaces are used [1].

The damage model consists of 8400 triangular Lagrange finite elements with two translational degrees of freedom per node, and a total of 4515 nodes. Furthermore, the following data for the damage model have been used: $k=0.001 \mathrm{~s}$ (time step size), $\kappa=$ $10^{-2}, \zeta_{*}=0.01, \lambda_{1}=2 . d-3, \lambda_{2}=5 \times 10^{9}, \lambda_{3}=7 \times 10^{-4}$.

\subsection{Results}

The failure load for the contact model of 40 interfaces is $87.14 \mathrm{KN}$. This limit load compares well with the one obtained by the damage model, which is equal to $90 \mathrm{KN}$. In Figure 1(b) the force - displacement diagrams of the two methods are compared. Moreover, both methods predict the same, well-known, mechanism of collapse. A four hinges mechanism arise in case of a quarter span load. The same conclusion arises from both experimental research [8] and the classical collapse mechanism method of Heyman [3]. The above results are schematically shown in Figure 2(a),(b). In Figure 2(b) also the damage field over the deformed configuration (deformations multiplied by a factor 50) is plotted. 

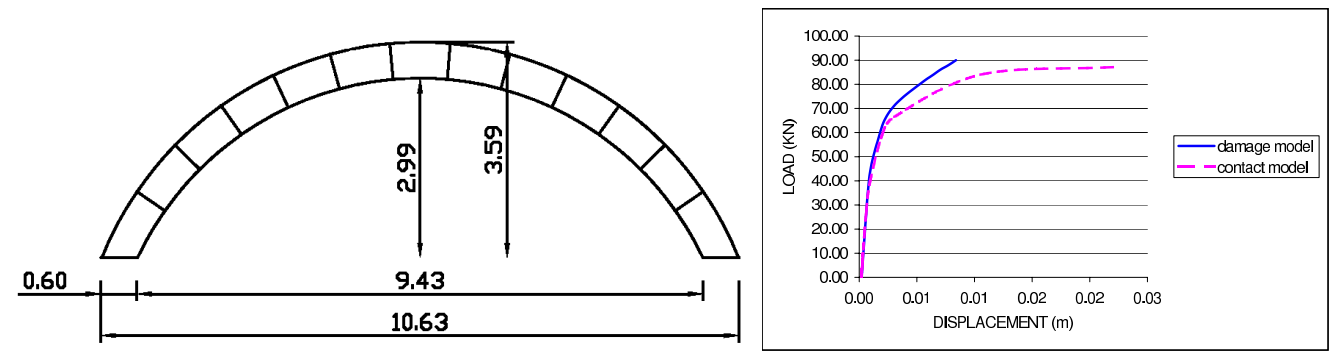

Fig. 1. (a) Geometry (m) of the masonry bridge-12 contact interfaces (b) Forcedisplacement diagram
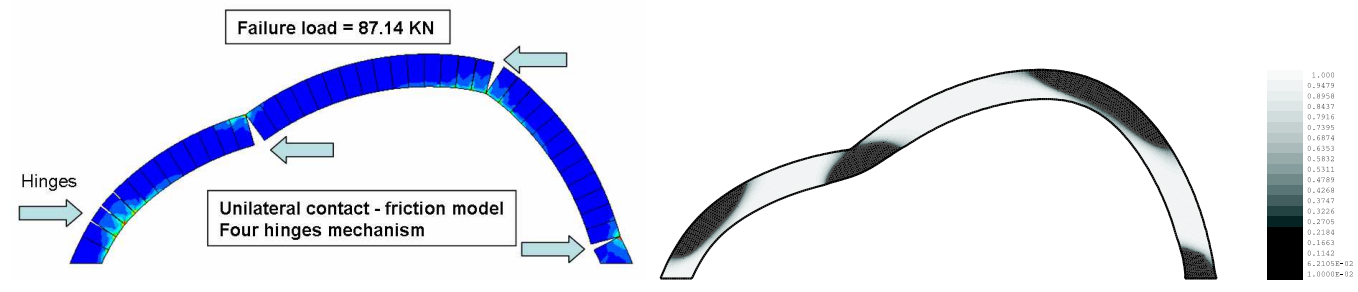

Fig. 2. Collapse mechanism from (a) unilateral contact-friction model (b) Damage model

\section{CONCLUSIONS}

The collapse mechanism of both contact and damage models at failure coincides with the one predicted by the classical collapse mechanism method of Heyman. The failure load obtained by the two methods is almost identical as well. However, there is a divergence in the force - displacement diagrams where the damage model has an ascending branch at failure. Further investigation, including for example parameter identification, will possibly lead to better comparison results.

\section{ACKNOWLEDGEMENTS}

The results presented here are based on the results obtained within the research project "Smart Systems. New Materials, Adaptive Systems and Their Nonlinearities. Modeling, Control and Numerical Simulation" Supported by the European Union with contract number HPRN-CT-2002-00284 and the PhD Theses of the first two authors.

\section{REFERENCES}

[1] G. A. Drosopoulos, G. E. Stavroulakis, C. V. Massalas, Limit analysis of a single span masonry bridge with unilateral frictional contact interfaces, Engineering Structures 28 (2006) 18641873. 
[2] Campo M, Fernández JR, Kuttler KL, Shillor M., Quasistatic evolution of damage in an elastic body: numerical analysis and computational experiments Applied Numerical Mathematics $\mathbf{5 7}$ (2007) (9) 975-988.

[3] Heyman J. The masonry arch, England: Ellis Horwood Series In Engineering Science, 1982.

[4] Haslinger J, Miettinen M, Panagiotopoulos PD., Finite element method for hemivariational inequalities, Theory, methods and applications. Dordrecht (The Netherlands): Kluwer Academic Publishers; 1999.

[5] Frémond M, Nedjar B., Damage in concrete: the unilateral phenomenon, Nuclear Engineering and Design 156 (1995) 323-335.

[6] Frémond M, Nedjar B., Damage, gradient of damage and principle of virtual work, International Journal of Solids and Structures 33 (1996) 1083-1103.

[7] Page J., Load tests to collapse on two arch bridges at Strathmashie and Barlae, Department of Transport, TRRL Research Report 201, Crowthorne (England): TRL; 1989.

[8] Page J., Masonry arch bridges - TRL state of the art review. London (England): HMSO; 1993.

Received July 22, 2009

\section{TIẾP XÚC MộT CHIỀU VÀ PHÂN TÍCH HƯ HỎNG TRONG VÒM ĐÁ CONG}

Trong nghiên cứu này tải trọng phá hủy cực hạn và cơ chế phá hủy của cầu đá được tính toán sử dụng (a) mô hình đàn hồi từng khúc với ma sát tiếp xúc một chiều và (b) mô hình hư hỏng liên tục. Theo mô hình tiếp xúc, ta xem xét mặt tiếp xúc mô phỏng thế năng của vết nứt và vét nứt bắt đầu khi các mặt tiếp xúc mở hoặc trượt đi. Mô hình thứ hai làm việc với hư hỏng vật liệu bao gồm sự phát triển các vết nứt micro bên trong và ảnh hưởng đến khả năng chịu tải của vật liệu. Trong bài báo kết quả của hai mô hình được so sánh.

Từ khóa: Vòm đá cong, phân tích giới hạn, tiếp xúc một chiều, mô hình hư hỏng liên tục 